\title{
Palm leaf catechins improved insulin-related pathways in diabetic rats
}

\author{
Nordanial Rohimi ${ }^{\mathrm{a}, \mathrm{b}}$, Rosalina Tan Roslan Tan ${ }^{\mathrm{b}}$, Nurul'Ain Abu Bakar ${ }^{\mathrm{a}, \mathrm{c}}$, Suhaila Mohamed ${ }^{\mathrm{a}, \mathrm{b}^{*}}$ \\ Institute of Bioscience, Universiti Putra Malaysia, 43400 Serdang, Selangor, Malaysia \\ ${ }^{b}$ Faculty of Food Science and Technology, Universiti Putra Malaysia, 43400 Serdang, Selangor, Malaysia \\ 'Institute of Pathology, Laboratory and Forensic Medicine (I-PPerForM), Faculty of Medicine, Universiti Teknologi MARA, 47000 Sungai \\ Buloh, Selangor, Malaysia
}

Received 2nd October 2020 / Accepted 28th September 2021

\begin{abstract}
Catechin-rich oil-palm leaf extract (OPLE) (Elaeis guineensis) was previously demonstrated to possess benefits for diabetes and cardio metabolic health (vasodilation, antioxidant, cardiovascular, antihypertensive, anti-inflammatory, hepatoprotective and nephroprotective properties) in animal models. For insights into OPLE anti-diabetic mode-of-action and possible toxicity, the effects of dietary OPLE on insulin-signaling pathways mRNA expressions in the liver, kidney, pancreas, and spleen of normal and diabetic rats were examined. Type-2-Diabetes Mellitus (T2DM) were induced by chronic high-fat diet and streptozotocin $(35 \mathrm{mg} / \mathrm{kg}$ ) intraperitoneal injection. The OPLE (100 mg/kg body weight) were fed daily to normal and T2DM-induced rats. The OPLE suppressed hyperglycaemia and excessive weight gain in the T2DM rats, and appeared harmless to normal rats. The OPLE supplementation significantly $(\mathrm{p}<0.05)$ modulated the mRNA expressions of phosphatidylinositol-3 kinase (PIK3R1); insulin signaling receptor (INSR); insulin-receptor substrates 1 and 2; and ectonucleotide pyrophosphatase-1 (ENPP1) especially in the livers of normal rats and the spleen of diabetic rats. Results suggested the OPLE probably help prevent diabetes in healthy mammals and ameliorate the immune functions of diabetic mammals. The OPLE improved the antioxidant defence responses, insulin-pathways mRNA expressions in the normal and diabetic rats; suppressed hyperglycaemia and excessive weight gain in T2DM rodents without observable liver or kidney toxicity at the dose used.
\end{abstract}

Keywords: catechins, diabetes, insulin pathways, liver, mRNA, oil-palm leaf

\section{INTRODUCTION}

Palm leaves are under-utilized, agro-waste from the palm oil industry. The oil-palm (Elaeis guineensis) leaf alcoholic extract (OPLE) contains high amounts of green tea catechins and flavonoids (Jaffri et al., 2011a). The green tea catechins demonstrated benefits against diabetes (Rosalina Tan et al., 2011), inflammation, cancer, arthritis, bacterial/virus infection, oxidative stress, angiogenesis, neuropathy and hypercholesterolaemia (Khan \& Mukhtar, 2007; Mohamed, 2014). The oil-palm leaves are known to be good ruminant feed and have been as such for decades without observable toxicity.

The OPLE has cardiovascular protective properties by maintaining coronary arteriole walllumen ratio under hypertension (Jaffri et al., 2011b), inducing vasorelaxation (Runnie et al., 2004), and inhibiting lipoprotein oxidation (Salleh et al., 2002). Animal model studies showed dietary OPLE was protective against inflammation (Anyanji et al., 2013), cardiovascular disorders (Jaffri et al., 2011), hepatopathy (Jaffri et al., 2011),

\footnotetext{
*Author for correspondence: Suhaila Mohamed, Level 4, Institute of Bioscience, Universiti Putra Malaysia, 43400 Serdang, Selangor, Malaysia. Email-suhaila@upm.edu.my; mohamed.suhaila@gmail.com
} 
neuropathy (Mohamed et al., 2013), oxidative tension and nephropathy (Mohamed, 2014; Rosalina Tan et al., 2011).

Almost $90 \%$ of diabetes are linked to insulin resistance or impaired cell response to insulin, caused by prolonged excessive blood insulin levels (Type-2 diabetes or T2DM). The T2DM treatment tries to focus on reducing unbalanced liver glucogenesis, increasing insulin sensitivity, enhancing insulin production, amending insulin signaling pathways, preventing obesity, regulating lipid metabolism and controlling lipotoxicity. The T2DM metabolic disorder is characterized by dyslipidaemia, hyperglycaemia, hypertension, atherosclerosis, inflammation and prothrombotic conditions.

Genes involved in the insulin signaling pathways include the ENPP1 (Ectonucleotide pyrophosphatase-1) that inhibits the tyrosine phosphorylation at the insulin receptors (INSR); insulin-receptor substrate 1 and 2 (IRS-1 and IRS2); phosphatidylinositol-3 kinase (PIK3R1), and mitogen-activated protein kinase MAPK8IP1 (Cao et al., 2007). The T2DM changes the insulin receptors (IRS1/IRS2-PI3K) functionality, signaling, protein kinase $\mathrm{B}$ and $\mathrm{C}$ (PKB and $\mathrm{PKC})$ activities and MAPK signaling (Fröjdö et al., 2009). The glucose metabolism is influenced by the hexosamine biosynthetic pathway genes, namely glycoprotein PC-1, glucose transporters 4 and 2 (GLUT-4 and GLUT-2), and the diabetesassociated peptide; amylin or IAPP (Islet Amyloid Polypeptide) (Cao et al., 2007).

A comparison of four different Type 2 diabetes rat models showed that the high-fat diet with low-dose STZ injections is a suitable and appropriate animal model which is analogous to the human T2DM, with evidences of insulin resistance and similar changes in IRS-1 or Akt phosphorylation using soleus muscle from each model (Chao et al., 2018). For insights into OPLE anti-diabetic mode-of-action and possible toxicity, the effects of dietary OPLE on insulinsignaling pathways mRNA expressions in the liver, kidney, pancreas, and spleen of normal and T2 diabetic rats were examined. This research investigated the influence of catechin-rich OPLE in normal and diabetic rats, for modulating glucose metabolic responses, by monitoring insulin pathways related genes such as PIK3R1, INSR, IRS1, IRS2, ENPP1, IAPP mRNA expressions, together with its effects on the liver and kidney.

\section{MATERIALS AND METHODS}

\section{Plant materials}

Oil-palm Leaves from Universiti Putra Malaysia were washed, dried in a $45^{\circ} \mathrm{C}$ oven, milled and soaked in 100\% ethanol (Merck, Germany) (ratio 1:10), overnight. The filtrate, was then rotary evaporated to dryness for producing the oil-palm leafs extract (OPLE) (Jaffri et al., 2011). The hydrolysed OPLE $(80 \mathrm{mg}$ in $6 \mathrm{M} \mathrm{HCl}$, refluxed for 2 hours at $95^{\circ} \mathrm{C}$ ) were cooled, filtered (0.4um Whatman nylon membrane) and analysed with reverse-phase-HPLC using reported procedures (Jaffri et al., 2011). The peaks were tentatively identified via the relative retention times of $>95 \%$ pure epicatechin gallate (ECG), epigallocatechin gallate (EGCG), (+)-catechin, (-)- epicatechin, and epigallocatechin (EGC). Myricetin, kaempferol, quercetin and rutin were used as internal and external standards. Quantitative determination of the detected compounds were calculated based on the total area of the peak in the calibration plot obtained from each standard compounds analyzed via HPLC.

\section{Animal (in vivo) studies}

Male rats (Sprague-Dawley) weighing $240 \pm 20 \mathrm{~g}$, were supplied by Universiti Putra Malaysia (Faculty of Veterinary medicine), and kept in polypropylene cages at ambient temperatures, with 12:12 h light:dark cycle. The rats were acclimatised for 14 days on tap water and rat chow containing $3 \%$ fat, $22 \%$ protein, $50 \%$ carbohydrate, $5 \%$ fiber and $3.2 \mathrm{kcal} / \mathrm{g}$ (Gold Coin Sdn. Bhd., Klang, Malaysia). The experimental protocol adhered closely to the approved University Putra Malaysia institutional animal ethical guidelines (UPM/FPSK/PADS/BR$\mathrm{UUH} / 00360)$. The rats were grouped into five categories $(n=6)$; normal non-treated control, normal+100 mg OPLE / kg body weight, diabetic non-treated control, diabetic $+100 \mathrm{mg} / \mathrm{kg}$ OPLE dissolved in drinking water and a positive control group (diabetic $+250 \mathrm{mg} / \mathrm{kg}$ oral metformin). Metformin was used merely as a reference for the comparing the effects on the fasting blood sugar 
level. Type-2 diabetes were induced with a high calorie diet containing $21 \%$ fat, $19.7 \%$ protein and $43.3 \%$ carbohydrate (Total $4.3 \mathrm{kcal} / \mathrm{g}$ ) for a month. They were then intraperitonially injected with $35 \mathrm{mg} / \mathrm{kg}$ Streptozotocin (Sigma-Aldrich, USA) (Motshakeri et al., 2013). After one week induction, rats with 15 hours fasting blood glucose (FBG) of over $150 \mathrm{mg} \mathrm{dl}^{-1}\left(8.3 \mathrm{mmol} \mathrm{l}^{-1}\right)$ were confirmed as hyperglycaemic/diabetic. The $100 \mathrm{mg} / \mathrm{kg}$ oral dose is based on the recommended dose from earlier studies (Jaffri et al., 2011; Rosalina Tan et al., 2011). The doseresponse study for the effects of OPLE on diabetes have been reported previously (Rosalina Tan et al., 2011), hence was not repeated in this study. After two weeks of treatment, the rats were exsanguinated under anaesthesia $(50 \mathrm{mg} / \mathrm{kg}$ ketamine and $5 \mathrm{mg} / \mathrm{kg}$ xylazine) for tissue mRNA analysis. The livers, pancreas, spleens and kidneys were isolated, weighed and cleaned with cold saline, before being stored in $\mathrm{RCl}$ solution at $80^{\circ} \mathrm{C}$ for mRNA analysis.

Another similar set of four groups of rats $(n=10)$; [normal non-treated control, normal +100 mg OPLE / $\mathrm{kg}$ body weight, diabetic non-treated control, diabetic $+100 \mathrm{mg} / \mathrm{kg}$ OPLE dissolved in drinking water] were kept for five weeks to evaluate their kidney and liver histopathological conditions after exsanguination under anaesthesia.

Blood were kept in heparinised tubes, at $0^{\circ} \mathrm{C}$ before centrifuging at $3000 \mathrm{~g}$ for 10 minutes to obtain the plasma. The separated red blood cells $(\mathrm{RBC})$ were rinsed and repeatedly centrifuged thrice with saline. Both $\mathrm{RBC}$ and plasma were stored at $-80^{\circ} \mathrm{C}$ before use.

The liver and kidneys were sliced and preserved in $10 \%$ neutral buffered formalin. The residual tissues were kept at $-80^{\circ} \mathrm{C}$ and analysed within four months. The antioxidant enzymes and malondialdehyde (MDA the lipid peroxidation biomarker), biochemical analysis and homogenate protein content were analysed as previously described (Matanjun et al., 2010). The liver and kidney injury indicators [blood aspartate transaminase (AST), blood alanine transaminase (ALT), blood urea nitrogen (BUN), plasma creatinine, and plasma triglycerides levels were analysed using the auto-analyzer (Roche/Hitachi, Germany) and commercial kits (Roche Diagnostics). Liver and kidney samples $(5 \mu \mathrm{m})$ were treated for hematoxylin-eosin (H\&E) staining (Matanjun et al., 2010).

\section{$R T-q P C R$ mRNA analysis}

The RNA were isolated using Ribopure RNA extraction kit (Ambion, Austin, TX, US). About $50 \mathrm{mg}$ of the organ tissues were processed to eliminate DNA, proteins and other compounds. The extracted RNA concentrations, purity and integrity were tested using the NanoDrop 2000 UV-Vis Spectrophotometer (Thermo Scientific, Wilmington, USA), then stored at $-80^{\circ} \mathrm{C}$ for the RT-PCR.

The genes studied and the primers constructed using the NCBI blast primer design software, and GenomeLab eXpress Profiler software (GeXPS) are summarised in Table 1. The RNA (50 ng) were reverse transcribed with multiplex universal reverse primers, using GenomeLab $^{\text {TM }}$ GeXP Start Kit (Beckman Coulter). The RT reaction was performed in a thermal-cycler at: $48^{\circ} \mathrm{C}$ for $1 \mathrm{~min} ; 37^{\circ} \mathrm{C}$ for $5 \mathrm{~min}$; $42^{\circ} \mathrm{C}$ for $60 \mathrm{~min} ; 95^{\circ} \mathrm{C}$ for $5 \mathrm{~min}$ and then held at $4{ }^{\circ} \mathrm{C}$.

The fragment size range was 150-350 nt with a 7-nucleotide minimum separation size between each PCR product. Besides the 11 genes of interest, each panel has an internal control gene (Kanr) and five normalization genes (ACTB, CYOA, EF1, GAPDH and ATPSYN). The reverse primers contained 20 nucleotides matching the selected gene and were labelled to a 19-nucleotide general reverse order. The forward primers contained 20 nucleotides conforming to the selected gene and were tagged to a 18 nucleotides universal forward sequence. All primers were from Proligo (France SAS), supplied by Sigma Aldrich from rat (rattus norvegicus) gene sequence adopted from the NCBI (National Center for Biotechnology Information) GenBank Database at http://www. ncbi.nlm.nih.gov. GeXPS primer stocks were dissolved in nucleasefree water to $500 \mathrm{nM}$ for reverse primer sets, and to $200 \mathrm{nM}$ for forward primer (Table 1). 
Table 1. Selected genes and primer sequence of the genes.

\begin{tabular}{|c|c|c|c|c|}
\hline Gene & Size & Function & Forward Primer & Reverse Primer \\
\hline \multirow[t]{2}{*}{ GAPDH } & 125 & Housekeeping genes & AGGTGACACTATAGAATAATGACTC & GTACGACTCACTATAGGGAAGCATC \\
\hline & & & TACCCACGGCAAG & ACCCCATTTGATGT \\
\hline \multirow[t]{2}{*}{ ATPSYN } & 135 & Housekeeping genes & AGGTGACACTATAGAATAAGTGACC & GTACGACTCACTATAGGGAACAATC \\
\hline & & & ACAGCGTTTCCTT & ATCCCACCCATGAT \\
\hline \multirow[t]{2}{*}{ EF1 } & 150 & Housekeeping genes & AGGTGACACTATAGAATAAAATGAC & GTACGACTCACTATAGGGACAGCAT \\
\hline & & & CCACCAATGGAA & CACCAGACTTCAA \\
\hline \multirow[t]{2}{*}{ CYOA } & 157 & Housekeeping genes & AGGTGACACTATAGAATACGAGCTG & GTACGACTCACTATAGGGAGATGCC \\
\hline & & & TTTGCAGACAAAG & AGGACCTGTATGCT \\
\hline \multirow[t]{2}{*}{ ACTB } & 164 & Housekeeping genes & AGGTGACACTATAGAATAGTGGGTA & GTACGACTCACTATAGGGACTGGGT \\
\hline & & & TGGGTCAGAAGGA & CATCTTTTCACGGT \\
\hline \multirow[t]{2}{*}{ ENPP1 } & 171 & Inhibition of insulin signalling & AGGTGACACTATAGAATACATGACA & GTACGACTCACTATAGGGACAGATT \\
\hline & & & CCGTACTGCGAAG & TTCTTGACTGCGGA \\
\hline \multirow[t]{2}{*}{ GFPT2 } & 178 & Hexosamine biosynthesis & AGGTGACACTATAGAATAAGTCATT & GTACGACTCACTATAGGGATGTCCG \\
\hline & & & CAGCAGTTGGAAGG & ATATAAGACGGGGA \\
\hline \multirow[t]{2}{*}{ INSR } & 185 & Insulin signalling receptor & AGGTGACACTATAGAATATCCGGGA & GTACGACTCACTATAGGGATCAATG \\
\hline & & & GAGGATGTGAGAC & ACCGAGCAGTTCTCC \\
\hline \multirow[t]{2}{*}{ IAPP } & 192 & Hormone, glucose uptake & AGGTGACACTATAGAATACTCGGCC & GTACGACTCACTATAGGGAATATGT \\
\hline & & pancreas & ACT'TGAGAGCTAC & ATTGGATCCCACATTGG \\
\hline \multirow[t]{2}{*}{ IRS1 } & 199 & Insulin signalling transduction & AGGTGACACTATAGAATATCCAGAA & GTACGACTCACTATAGGGAAGGGAT \\
\hline & & & GCAACCAGAGGAC & GCATCGTACCATCT \\
\hline
\end{tabular}




\begin{tabular}{lllll}
\hline IRS2 & 211 & Insulin signalling transduction & $\begin{array}{l}\text { AGGTGACACTATAGAATAACCTACG } \\
\text { CAAGCATCGACTT }\end{array}$ & $\begin{array}{l}\text { GTACGACTCACTATAGGGACTCAAA } \\
\text { ATGTAGAATTGCTCCC }\end{array}$ \\
\hline MAPK8IP1 & 226 & MAPK signal transduction & $\begin{array}{l}\text { AGGTGACACTATAGAATACTACCCT } \\
\text { TCTGGGCATGAAA }\end{array}$ & GTACGACTCACTATAGGGAGATCTC \\
& & & CGAAAGGTCTTCATC \\
\hline PIK3R1 & 231 & Glucose clearance & AGGTGACACTATAGAATATTTTAAT & GTACGACTCACTATAGGGACGTACC \\
& & & CTCAGCGGAGTGGA & AGAAAGGTCCCATC \\
\hline TNF & 240 & Proinflammatory cytokines & AGGTGACACTATAGAATAAGAACTC & GTACGACTCACTATAGGGATTTGCT \\
& & & CAGGCGGTGTCTG & ACGACGTGGGCTA \\
\hline PPARG & 250 & Lipid and glucose regulation & AGGTGACACTATAGAATACTGTTAT & GTACGACTCACTATAGGGACGTGGT \\
& & & GGGTGAAACTCTGGG & AAAGGGTTTGATGTC \\
\hline RRAD & 260 & Insulin sensitivity & AGGTGACACTATAGAATAGATGTGC & GTACGACTCACTATAGGGATTGTCG \\
& & & CCATCATCCTAGTG & ACGAGCATTATCCTC
\end{tabular}

GAPDH, glyceraldehyde 3-phosphate dehydrogenase; ATPSYN, ATP synthase; EF1, elongation factor 1-alpha; CYOA, ubiquinol oxidase subunit II; ACTB, actin beta; ENPP1, ectonucleotide pyrophosphatase/phosphodiesterase 1; GFPT2, glutamine-fructose-6-phosphate transaminase 2; INSR, insulin receptor; IAPP, islet amyloid polypeptide; IRS1, insulin receptor substrate 1; IRS2, insulin receptor substrate 2; MAPK8IP1, mitogen-activated protein kinase 8 interacting protein 1; MAPK, mitogen activated protein kinase; PIK3R1, phosphoinositide-3-kinase regulatory subunit 1; TNF, tumor necrosis factor; PPARG, peroxisome proliferator-activated receptor gamma; RRAD, Ras related glycolysis inhibitor and calcium channel regulator. 
The PCR reaction concoction contained the cDNA reverse transcription reaction product $(9.3$ $\mu \mathrm{l})$; the forward universal primer set mix $(2 \mu \mathrm{l}) ; 25$ $\mathrm{mM} \mathrm{MgCl} 2(4 \mu \mathrm{l}) ; 0.7 \mu \mathrm{l}$ of Thermo Start Taq DNA polymerase (Thermo Fisher Scientific, Pittsburgh, PA) and $4 \mu$ l of $5 \times$ PCR Master Mix buffer (GenomeLab GeXP Start Kit; Beckman Coulter, inc). The amplification required an initial denaturation step $\left(95^{\circ} \mathrm{C}\right.$ for $\left.10 \mathrm{~min}\right)$, proceeded by 35 two-step cycles $\left(94^{\circ} \mathrm{C}\right.$ for $30 \mathrm{~s}$ and $55^{\circ} \mathrm{C}$ for $30 \mathrm{~s})$, and finally an extension cycle $\left(68^{\circ} \mathrm{C}\right.$ for 1 min), in XP Thermal Cyclers (BIOER; Technology, Germany).

The PCR products from multiplex primer reactions were diluted 1:4 in water, and $1 \mu l$ was added to $38.5 \mu \mathrm{l}$ sample loading solution along with 0.5 DNA size standard 400 (GenomeLab GeXP Start Kit; Beckman Coulter, Inc). The GeXPS system separated the PCR products by capillary gel electrophoresis and their dye signal strength were measured in arbitrary units (A.U.) of optical fluorescence minus the background signals. The data were first analyzed using the Fragment Analysis module of the GeXP system and then imported into the analysis module of eXpress Profiler software. The housekeeping genes (Actb, Gapdhs and 18S genes) were evaluated for consistency and stability, and the $18 \mathrm{~S}$ was most consistently expressed in all the organs, thus was selected for normalizing the other genes (Wu et al., 2019).

\section{Statistics}

All statistical analysis were done using Minitab 13 statistical software. The significant differences between the groups were analysed using a twoway analysis of variance (ANOVA), on the mean. This was followed by the Student-NewmanKeuls multiple range test for $\mathrm{p}<0.05$ significance level. Fold change in mRNA expressions (OPLE treated over non-treated groups) of $\geq 1.5$ indicate significance at $\mathrm{p} \leq 0.05$; Fold change of $\geq 2$ indicate significance at $\mathrm{p} \leq 0.02$ (Dalman et al., 2012).

\section{RESULTS}

The OPLE HPLC quantitative analysis (Figure 1) showed the OPLE contains mainly catechin $(3 \mathrm{~g}$ $\left.\mathrm{kg}^{-1}\right)$, epigallocatechin gallate $\left(2.8 \mathrm{~g} \mathrm{~kg}^{-1}\right)$, epigallocatechin (800 $\left.\mathrm{mg} \mathrm{kg}^{-1}\right)$, epicatechin gallate (500 $\left.\mathrm{mg} \mathrm{kg}^{-1}\right)$, epicatechin $\left(100 \mathrm{mg} \mathrm{kg}^{-1}\right)$ and their glucosides. The OPLE significantly suppressed the excessive body weight increase (obesity inclination) and hyperglycaemia in the T2DM rats without significantly affecting the body weight or blood glucose levels of normal rats (Figure 2).

Dietary OPLE significantly $(p<0.05)$ upregulated the IRS1 and IRS2 mRNA expressions, and downregulated IAPP expressions in the pancreas of healthy rats (Figure 3a). The OPLE significantly up-regulated the PIK3R1 mRNA expressions in the pancreas and livers of diabetic rats and significantly increased most of the insulin-related mRNA expressions in the livers of normal rats (Figure 3b).

The OPLE downregulated ENPP1 expression in the kidneys and spleens of the healthy rats significantly $(\mathrm{p}<0.05)$ (Figure 4$)$. The OPLE upregulated all the studied insulinpathways related genes in the diabetic rats' spleen and downrelated these genes in the spleen of normal OPLE treated rats (Figure 4b).

The diabetic rats' kidneys showed significant $(p<0.05)$ glomeruli injuries (sclerosis and inflammatory cells infiltration) unlike the normal control rats (Figure 5). These glomerular damages were significantly reduced with the OPLE supplementation. The normal rats on OPLE supplementation showed normal kidney and liver structures. The diabetic rats' livers showed vacuolations, swelling and hepatocytes necrosis and the OPLE treatment attenuated the abnormal hepatocyte numbers in these diabetes-induced rats (Figure 5) towards normal levels.

The control nontreated T2DM rats had $60 \%$ mortality after the fifth week of diabetesinduction. The mortality of the OPLE treated T2DM rats after the fifth week was only $10 \%$ (Figure 6a). The percentage abnormal hepatocytes, and hepatocellular enzymes (ALT and AST) leakage were highest in the non-treated control diabetic rats (Figure 6b), and the OPLE supplementation mitigated this increase. This suggests that the OPLE was hepatoprotective for T2DM at the daily dose used.

The BUN levels in the control non-treated T2DM rats were significantly $(\mathrm{p}<0.05)$ higher than normal (Figure 6c) and the OPLE supplementation insignificantly reduced it. Plasma 
creatinine and protein levels were insignificantly different between the groups.

The plasma MDA levels were very high in the control non-treated T2DM rats and were significantly reduced by the OPLE supplementation (Figure 6b). The red blood cells (RBC) SOD and catalase activities were lowest in the control non-treated T2DM rats and were amended to normal levels with the OPLE supplementation (Figure 6c). The high blood triglyceride levels in the control non-treated T2DM rats were significantly reduced by the OPLE treatment. All groups exhibited similar glutathione peroxidase GPx activities.

\section{DISCUSSION}

The OPLE HPLC profile showed significant catechin $\left(3 \mathrm{~g} \mathrm{~kg}^{-1}\right)$, epigallocatechin gallate $(2.8 \mathrm{~g}$ $\left.\mathrm{kg}^{-1}\right)$, epigallocatechin $\left(800 \mathrm{mg} \mathrm{kg}{ }^{-1}\right)$, epicatechin $\left(100 \mathrm{mg} \mathrm{kg}^{-1}\right)$, epicatechin gallate $\left(500 \mathrm{mg} \mathrm{kg}^{-1}\right)$ contents. These are most likely the main bioactive compounds responsible for the antihyperglycaemic effects. Catechins reduced FBG in hyperglycaemic rats by either promoting cells glucose uptake /metabolism or inhibiting hepatic gluconeogenesis (Kim, 2008).

Flavonoids affect insulin secretion, insulin resistance, apoptosis and pancreatic $\beta$-cells proliferation. Flavonoids amended hyperglycaemia via hepatocytes glucose metabolism; inflammation, tissues oxidation and glucose utilisation in the muscles and white adipose tissues (Babu et al., 2013). Catechins also inhibit the carbohydrates hydrolysing enzymes to delay glucose absorption hence help lower food glycaemic index (Lochocka et al., 2015). EGCG significantly reduced glucose absorption, inhibit the sodium-dependent glucose transporter, and enhanced insulin activity especially in T2DM by increasing insulin sensitivity (Hajiaghaalipour et al., 2015). Similarly, epicatechin gallate (ECG) potently suppressed glucose utilisation and the sodium-dependent glucose transporter, in Caco-2 cells to significantly reduce blood glucose levels (Brown et al., 2011). Here, the OPLE caused no significant changes in the relative expressions of any of the other monitored genes in any of these organs (e.g. TNF-proinflammatory cytokines; PPARg - involved in lipid and glucose regulation).

The IAPP is co-secreted with insulin (ratio 1:10 for IAPP:insulin) by the pancreatic islets $\beta$ cells, and may be an indicator of pancreatic $\beta$-cells health status and insulin secretion (Andrich \& Bieschke, 2015). The OPLE supplementation upregulated IAPP mRNA expressions (although insignificantly) in the diabetic rats' pancreas suggesting increased co-secreted insulin production (Jaikaran \& Clark, 2001). This is supported by the improved blood glucose levels (Figure 2). The OPLE downregulated IAPP expressions in healthy rats, signifying improved insulin efficiency, and protection against amyloidogenicity and cytotoxicity caused by high IAPP levels (Lopes et al., 2004). The IAPP slows gastric emptying, promotes satiety, and retards post-prandial spikes in blood glucose levels, reduces digestive juice secretions, food intake and obesity inclination (Andrich \& Bieschke, 2015). This is supported by the lower rate of body weight increase in the T2DM rats consuming OPLE (Figure 3a) as compared to the control nontreated T2DM rats. A small percentage of healthy volunteers in an earlier human studies on the effects of dietary OPLE on cognitive functions (Mohamed et al., 2013), reported slight weight reduction.

The ENPP1 is a negative modulator for insulin signaling, and chronic up-regulation of ENPP1 inhibits the cells' insulin receptor tyrosine kinase leading to insulin resistance. The ENPP1 (PC-1) down-regulation in diabetic mice' livers reportedly improved the blood glucose levels and glucose tolerance (Maddux et al., 2006). Here the OPLE down-regulated ENPP1 expression in the kidneys and spleens in the healthy control (Figure 4), and in the diabetic rats' pancreas, suggesting improved insulin-induced glucose transport in these organs, and improved feedback to the diabetic pancreas. The ENPP1 mRNA upregulation in the healthy rats' livers and diabetic rats' spleen is positively associated with the insulin receptor (INSR), IRS1 and IRS2 augmentations in these organs, and may indicate amended homeostasis responses (Zhou et al., 2009). 

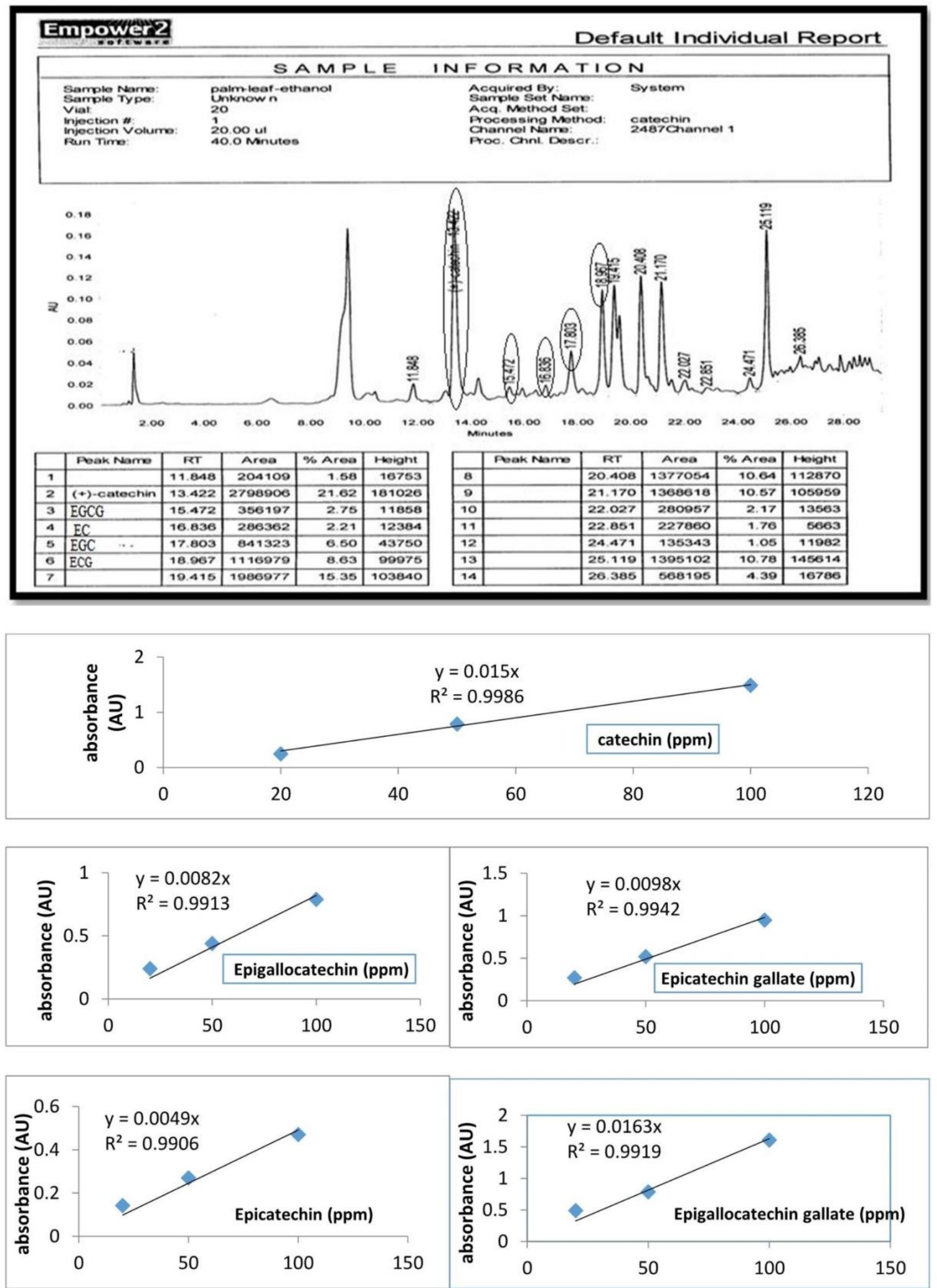

Figure 1. HPLC profile of oil-palm leaf extract used. 


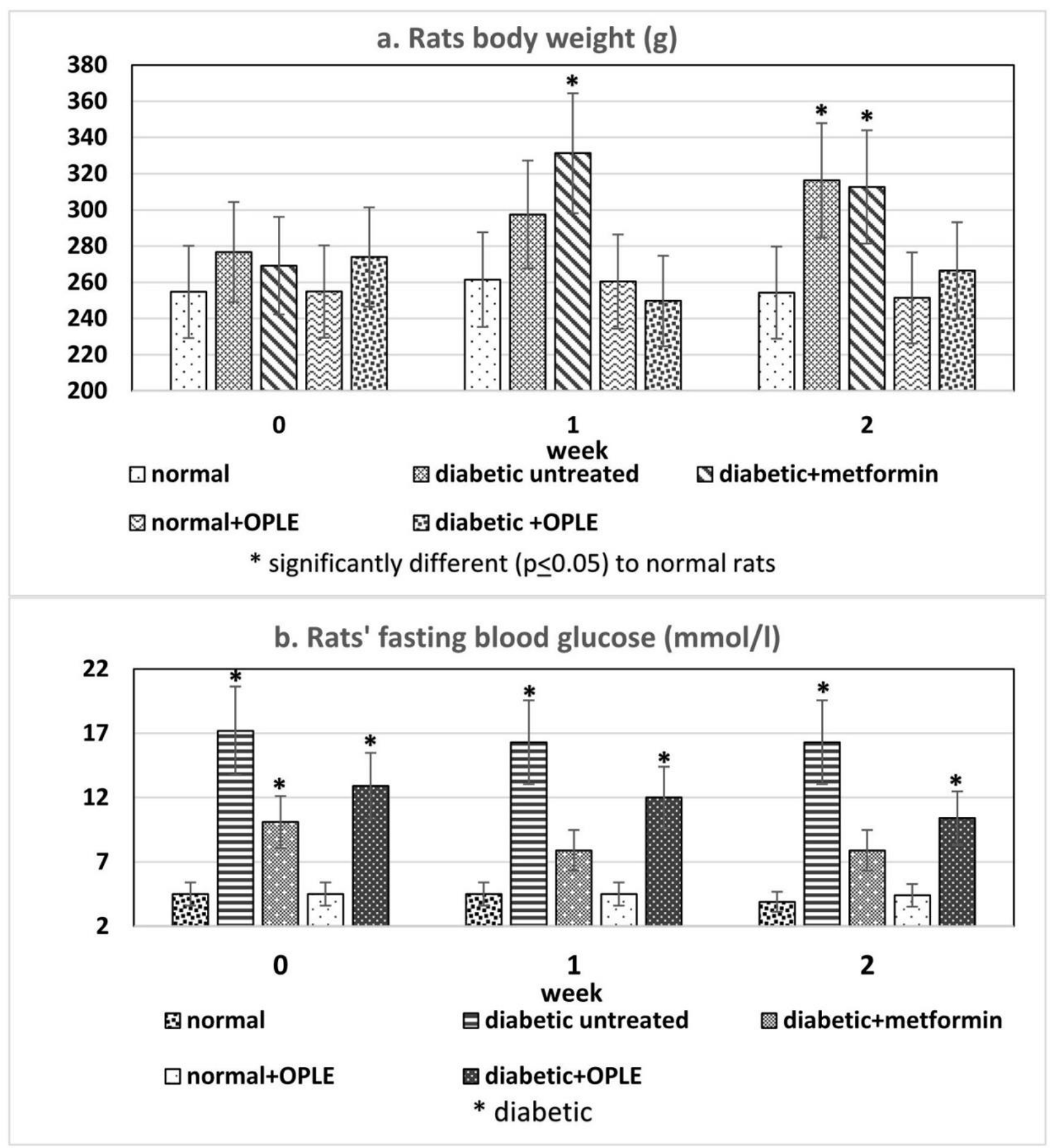

Figure 2. (a) Body weight gains (Normal healthy animals on Oil-palm Leaf Extract showed similar weight gain to normal healthy control rats; diabetic animals on Oil-palm Leaf Extract also showed weight gains similar to normal healthy control rats); (b) Fasting Blood glucose profile of healthy and diabetic rodents on normal diet and oil-palm leaf extract supplementation. Normal healthy animals on Oil-palm Leaf Extract showed similar blood glucose to normal healthy control rats; Diabetic rats on metformin, and Oilpalm Leaf Extract showed reduced blood sugar. 

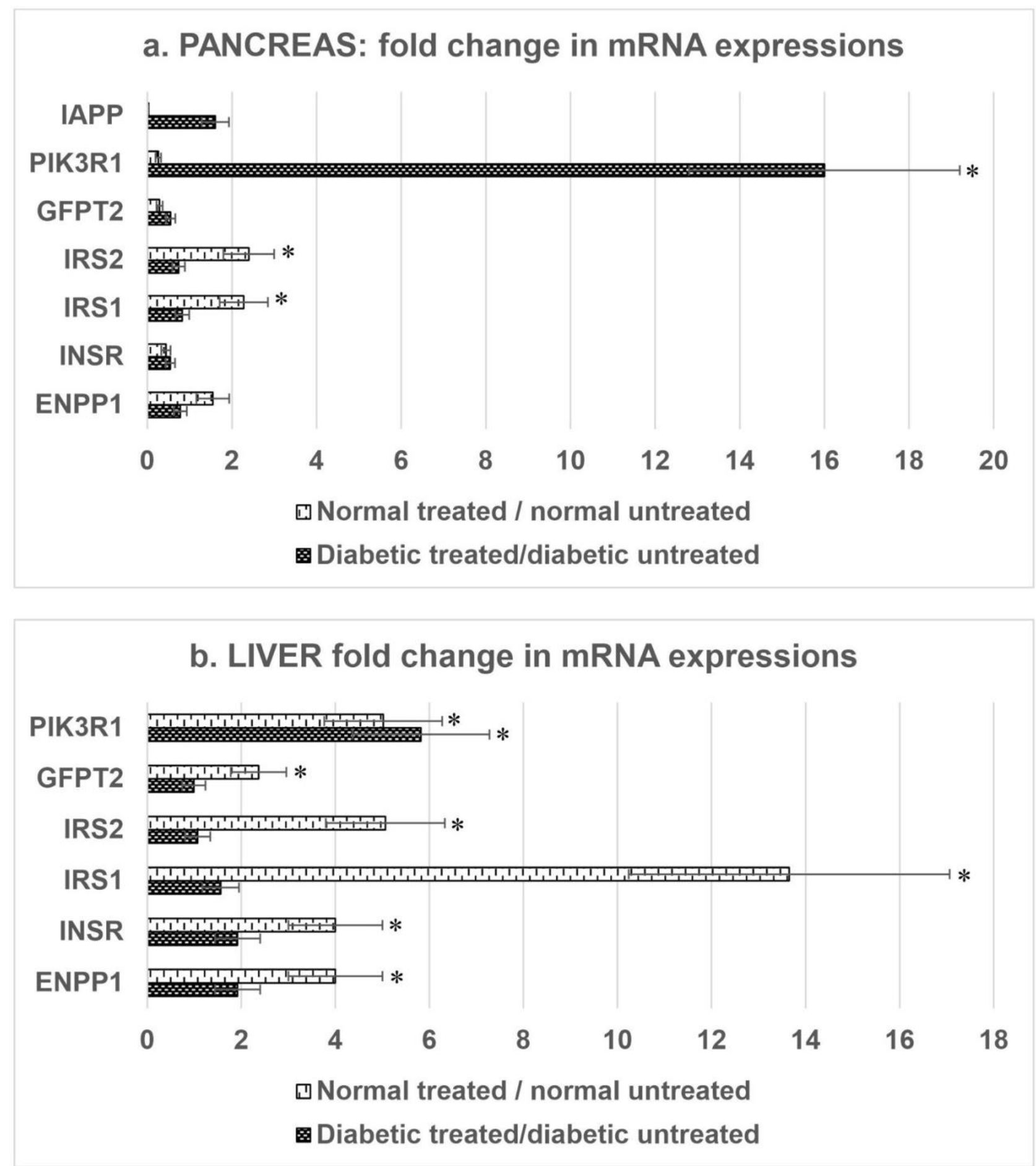

Figure 3. (a) Fold change in mRNA expressions (between Oil-palm Leaf Extract treated and control nontreated groups) in the pancreas of diabetic rats; (b) Fold change in mRNA expressions (between OPLE treated and control non-treated groups) in livers of normal and diabetic rats. Fold change of $\geq 1.5$ indicate significance at $\mathrm{p} \leq 0.05$; Fold change of $\geq 2$ indicate significance at $\mathrm{p} \leq 0.02$ (Dalman et al., 2012). 

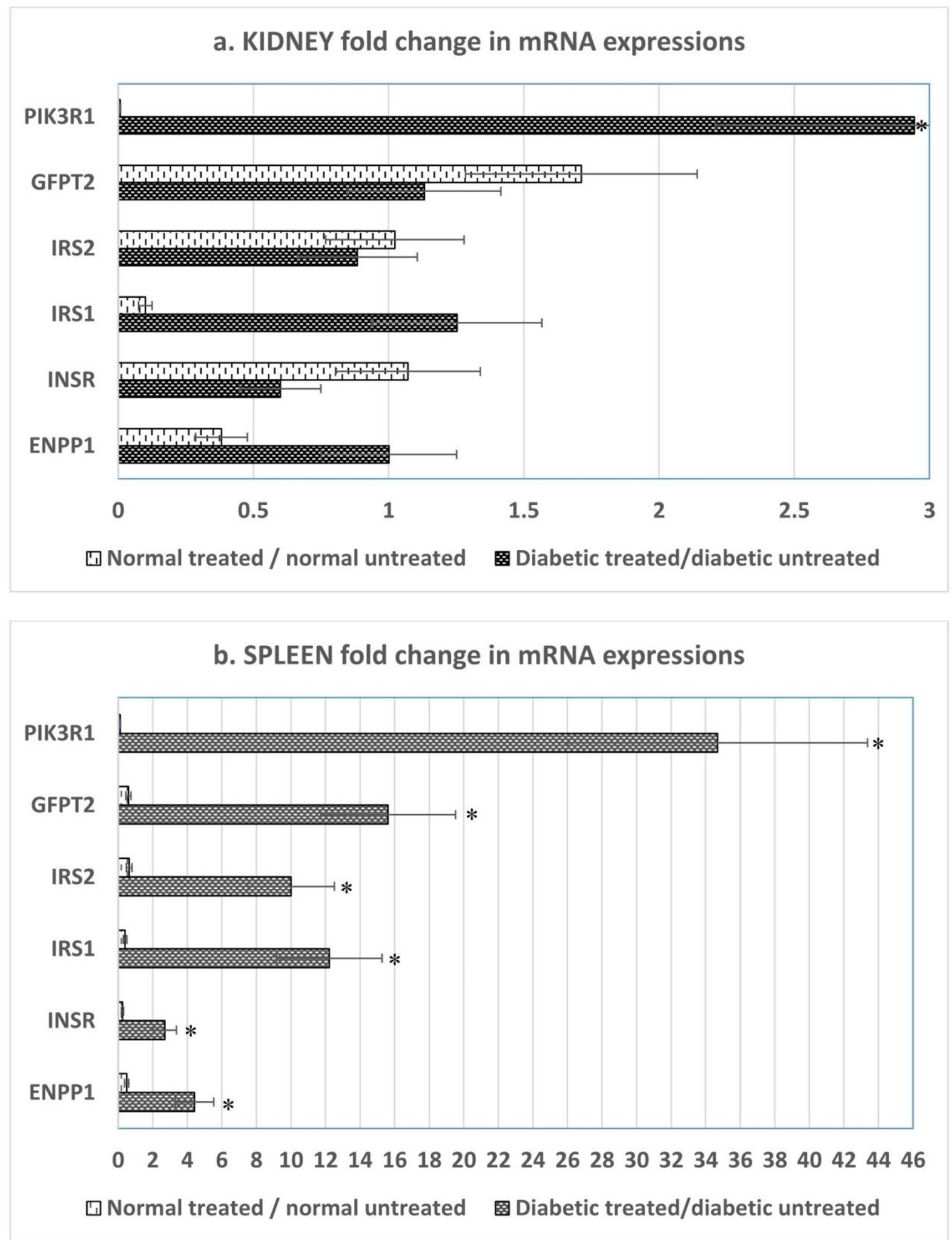

Figure 4. Fold change in mRNA expressions (between Oil-palm Leaf Extract treated and control nontreated groups) in the (a) kidneys and (b) spleens of normal and diabetic rats. Fold change of $\geq 1.5$ indicate significance at $\mathrm{p} \leq 0.05$; Fold change of $\geq 2$ indicate significance at $\mathrm{p} \leq 0.02$ (Dalman et al., 2012). 


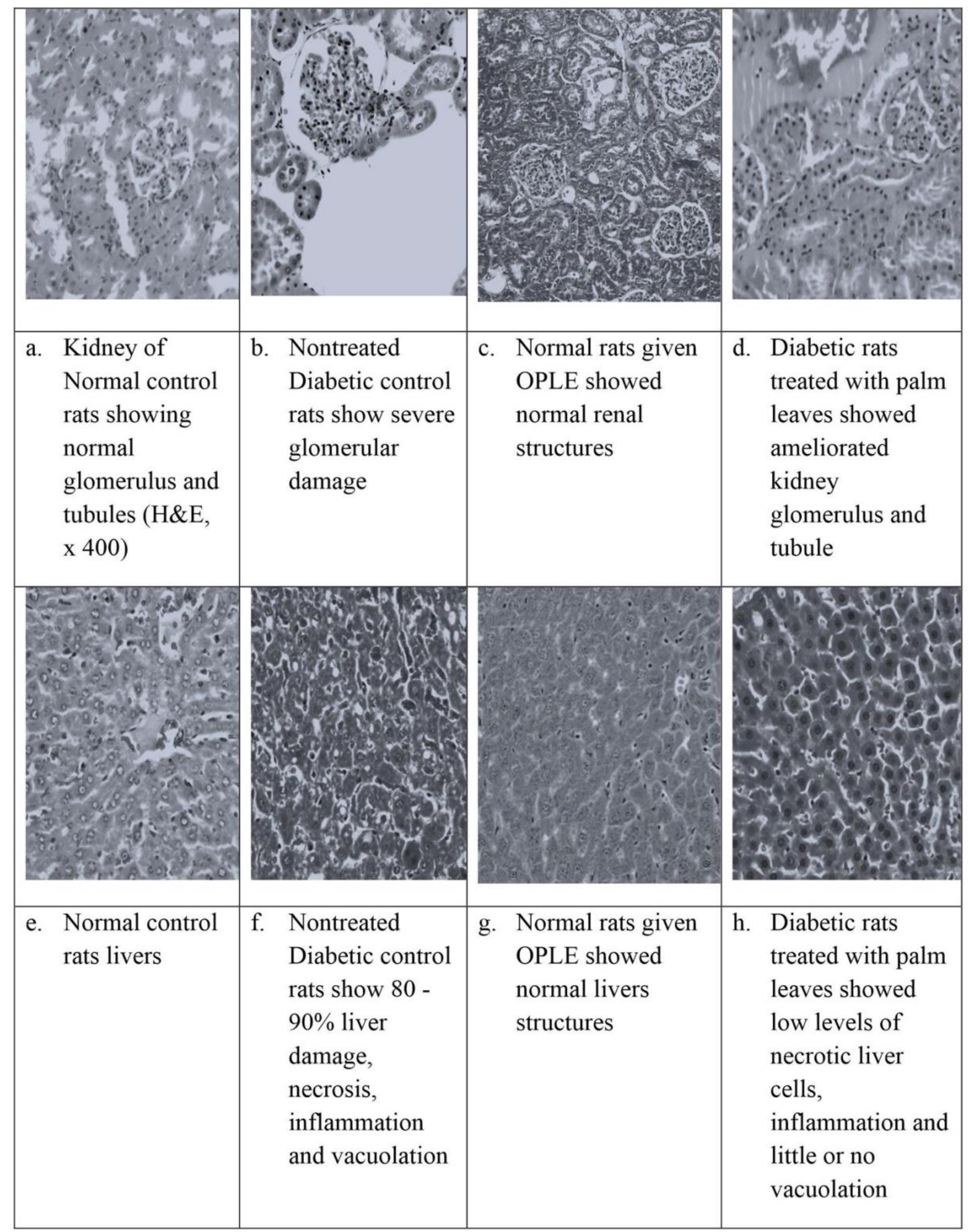

Figure 5. Effects of Oil-palm Leaf Extract on normal and diabetic rats' kidney and liver architectures under $400 \mathrm{X}$ magnification. 

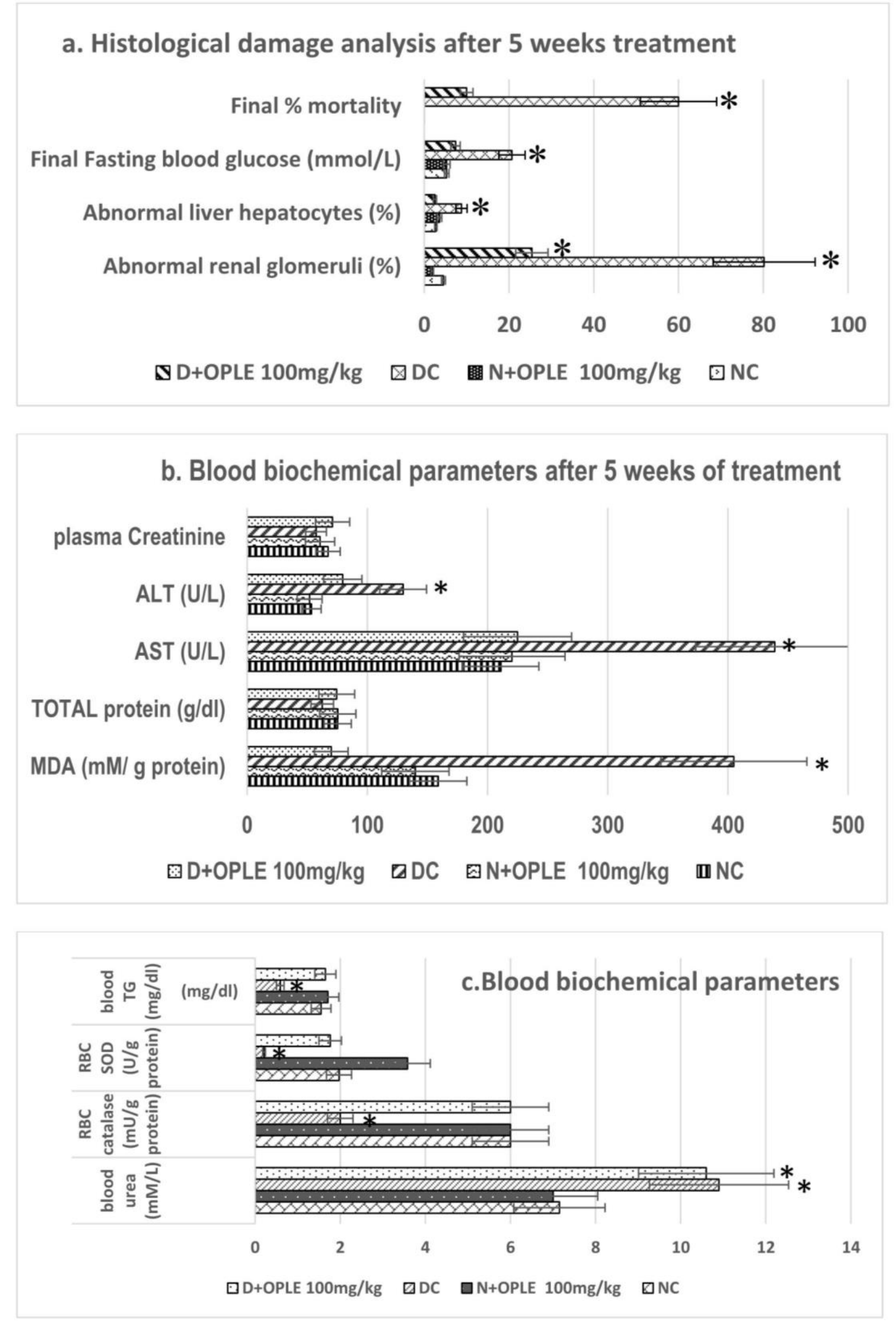

$\mathrm{DC}=$ Diabetic control;

NC: Normal control

Figure 6. Effects of Oil-palm Leaf Extract on percentage mortality, normal and diabetic rats hepatocytes, nephrons and blood biochemical parameters. 
The OPLE significantly $(\mathrm{p}<0.05)$ upregulated INSR, IRS1 and IRS2 mRNA expressions in normal and diabetic rats' livers, suggesting improved insulin sensitivity, or insulin signaling transduction. This would subsequently ameliorate glucose metabolism, translocation and insulin efficiency (Hanhineva et al., 2010). The INSR mRNA expressions were significantly correlated with lower FBG, HbA1c, triglyceride, and insulin levels in clinical T2DM patients, preclinically and in vitro (Fröjdö et al., 2009). The IRS1 and IRS2 are linked to insulin secretion regulation and insulin sensitivity. The insulin receptor substrates (IRS-1 to IRS-4) are activated by phosphorylation at the tyrosine residues by insulin receptor tyrosine kinase to support glucose transport by glucose transporter (GLUT4) into the tissue. The IRS phosphorylation activate the phosphatidylinositol-3 kinase (PI3K) and the Ras-MAPK pathways which help reduce hepatic glucose production (via gluconeogenesis and glycogenesis), and activate various anabolic signaling pathways that favour glucose homeostasis (Fröjdö et al., 2009).

The IRS-2 is also actuated by IL-4 for mediating glucose transport through the PI3Kinase signaling pathway (Fröjdö et al., 2009). The PI3K catalyses the phosphatidylinositol phosphorylation to give phosphatidylinositol-3phosphates which activate other signaling molecules, including serine kinase, GSK-3, the fork head transcription factors and the cAMP response element-binding protein. The OPLE significantly $(\mathrm{p}<0.05)$ upregulated the PIK3R mRNA expressions in the all the analysed organs (liver, pancreas, kidney and spleen) of diabetic rats, suggesting that the OPLE may also improve glucose transport (Cao et al., 2007). The PIK3R1 is a p85 regulatory subunit which encode the $\mathrm{PI} 3 \mathrm{~K}$, and increases glucose uptake or glycogen synthesis in insulin-sensitive tissues (Cao et al., 2007). Dysfunctional PIK3R1 causes insulin resistance via the PI3K hexosamine regulation (Suzuki et al., 2013). The significantly $(\mathrm{p}<0.05)$ upregulated PIK3R1 mRNA expressions in the diabetic rats' organs were supported by the ameliorated blood glucose levels and may help ameliorate kidney pressure.

The OPLE significantly $(\mathrm{p}<0.05)$ upregulated the INSR, IRS1, IRS2, PIK3R1, IAPP AND ENPP1 mRNA expressions in the diabetic rats' spleen. This suggested enhanced insulin signaling pathways/glucose translocation, which would subsequently improve immune responses for the T-helper cells cytokines production against tissue injuries, allergic reactions and infection (Andrich \& Bieschke, 2015). Spleen is the main immune system centre for synthesizing antibodies in the white blood cells, besides filtering blood, removing old blood cells throughout the liver and replacing them back by new $\mathrm{RBC}$ produced by the bone marrow, in the hematopoiesis process ( $\mathrm{Lim}$ et al., 2016).

The OPLE caused significant $(\mathrm{p}<0.05)$ downregulation of ENPP1, INSR, IRS1 and PIK3R1 mRNA expressions in control normal rats' spleen, which may be due to improved energy utilisation in the spleen.

Diabetes related liver tissue architecture disruption and vacuolation, indicates hepatocellular injury, which induces low-grade inflammation, dyslipidemia and insulin resistance. The OPLE influenced the endothelium for regulating vascular tone, homeostasis (Abeywardena et al., 2002) and suppressed inflammation (Abeywardena et al., 2002; Anyanji et al., 2013) thus was probably hepatoprotective through these mechanisms. Plasma ALT is a better indicator of liver inflammation than AST, since it is found mainly in the liver, and AST may increase in acute liver damage or other diseases involving liver parenchymal cells, red blood cells, cardiac muscle, skeletal muscle, kidney and brain tissue injuries (Jaffri et al., 2011b).

The significantly elevated BUN levels in the diabetic rats indicated glomerular damages that was verified by the dilated tubules and increased peritubular space. This was not significantly reduced by OPLE supplementation. Excess protein infiltration, and inflammation in diabetes, cause tubular damage. The tubular structural abnormalities would cause diuresis, impair urine concentrating ability and eventually polydipsia as observed in all the T2DM rats. Catechins with its anti-hyperglycaemia and anti-hypertension properties, may help inhibit kidney damages. Significant plasma BUN or creatinine levels elevations are only observed, when the nephrons are over $70 \%$ dysfunctional. The normal rats supplemented with OPLE showed normal tubular cells. 
The improved MDA, SOD and catalase levels, indicated ameliorated endogenous antioxidant defence with the OPLE supplementation in T2DM rats. Excessive lipid peroxidation is associated with antioxidant deficiency, that produces toxic aldehydes that can damage membrane proteins, leading to the cytoplasmic enzymes leakage (Jaffri et al., 2011b). Green tea catechins are similarly known to protect against various tissue damage (Burckhardt et al., 2008), insulin sensitivity (Prasain et al., 2010), inflammation, endothelial apoptosis (Curin \& Andriantsitohaina, 2005), vascular health (Galleano et al., 2012), and vascular homeostasis (Moore et al., 2009).

\section{CONCLUSION}

The dietary OPLE significantly $(p<0.05)$ modulated insulin associated pathways (INSR, IRS1, IRS2, PIK3R1, IAPP, and ENPP1) mRNA expressions especially in the normal rats' livers and the diabetic rats' spleen to increased insulin sensitivity, insulin signaling transduction and glucose translocation into these tissues. The mRNA expressions advocated that OPLE may help prevent T2DM in healthy rats and improve the metabolic and immune functions of diabetic rats. The OPLE up-regulated IAPP expressions suggest improved insulin production, satiety, weight-control and blood glucose homeostasis in these animals. The OPLE demonstrated antihyperglycaemic and anti-obesity effects on T2DM rat models. These findings may be confirmed or expanded by further studies on protein expressions in animal diabetic models or in controlled clinical intervention studies.

\section{ACKNOWLEDGEMENTS}

We thank Universiti Putra Malaysia for the limited research grant and for providing the facilities. This work was supported by the Universiti Putra Malaysia (Research University Grant no. RUGS 9386700). Nordanial Rohimi, Rosalina Tan Roslan Tan and Dr Nurul'Ain Abu Bakar executed the experiments, planning, data collection, and manuscript preparation. Suhaila Mohamed is the grant recipient, main supervisor, project planning coordinator and manuscript writing/editing. All authors read and approved the final version of the manuscript.

\section{CONFLICT OF INTEREST}

The authors have declared that no conflict of interest exists.

\section{REFERENCES}

Abeywardena, M., Runnie, I., Nizar, M., Suhaila, M., \& Head, R. 2002. Polyphenol-enriched extract of oil palm fronds (Elaeis guineensis) promotes vascular relaxation via endotheliumdependent mechanisms. Asia Pacific Journal of Clinical Nutrition 11 (Suppl 7): S467-72.

Andrich, K., \& Bieschke, J. 2015. The effect of (-)-epigallocatechin-(3)-gallate on amyloidogenic proteins suggests a common mechanism. Advances in Experimental Medicine and Biology 863: 136-61.

Anyanji, V. U., Mohamed, S., Zokti, J. A., \& Ado, M. A. 2013. Anti-inflammatory properties of oil palm leaf (Elaeis guineensis Jacq.) extract in aged rats. International Journal of Pharmacy and Pharmaceutical Sciences 5(Suppl 4): 134-136.

Babu, P. V. A., Liu, D., \& Gilbert, E. R. 2013. Recent advances in understanding the anti-diabetic actions of dietary flavonoids. The Journal of Nutritional Biochemistry 24(11): 1777-1789.

Brown, A. L., Lane, J., Holyoak, C., Nicol, B., Mayes, A. E., \& Dadd, T. 2011. Health effects of green tea catechins in overweight and obese men: a randomised controlled crossover trial. The British Journal of Nutrition 106(12): 1880-1889.

Burckhardt, I. C., Gozal, D., Dayyat, E., Cheng, Y., Li, R. C., Goldbart, A. D., \& Row, B. W. 2008. Green tea catechin polyphenols attenuate behavioral and oxidative responses to intermittent hypoxia. American Journal of Respiratory and Critical Care Medicine 177(10).

Cao, H., Hininger-Favier, I., Kelly, M. A., Benaraba, R., Dawson, H. D., Coves, S., Roussel, A. M., \& Anderson, R. A. 2007. Green tea polyphenol extract regulates the expression of genes involved in glucose uptake and insulin signaling in rats fed a high fructose diet. Journal of Agricultural and Food Chemistry 55(15): 6372-6378.

Chao, P.-C., Li, Y., Chang, C.-H., Ping, S. J., Juei-Tang, C., \& Cheng, K.-C. 2018. Investigation of insulin resistance in the popularly used four rat models of type-2 diabetes. Biomedicine \& Pharmacotherapy 101: 155-161.

Curin, Y., \& Andriantsitohaina, R. 2005. Polyphenols as potential therapeutical agents against cardiovascular diseases. Pharmacological Reports 57(Suppl): 97-107.

Dalman, M. R., Deeter, A., Nimishakavi, G., \& Duan, Z.-H. 2012. Fold change and p-value cutoffs significantly alter microarray interpretations. BMC Bioinformatics 13(Suppl 2).

Fröjdö, S., Vidal, H., \& Pirola, L. 2009. Alterations of insulin signaling in type 2 diabetes: A review of the current evidence from humans. Biochimica et Biophysica Acta (BBA) Molecular Basis of Disease 1792(2): 83-92. 
Galleano, M., Calabro, V., Prince, P. D., Litterio, M. C., Piotrkowski, B., Vazquez-Prieto, M. A., Miatello, R. M., Oteiza, P. I., \& Fraga, C. G. 2012. Flavonoids and metabolic syndrome. Annals of the New York Academy of Sciences 1259(1): $87-94$.

Hajiaghaalipour, F., Khalilpourfarshbafi, M., \& Arya, A. 2015. Modulation of glucose transporter protein by dietary flavonoids in type 2 diabetes mellitus. International Journal of Biological Sciences 11(5): 508-524.

Hanhineva, K., Törrönen, R., Bondia-Pons, I., Pekkinen, J., Kolehmainen, M., Mykkänen, H., \& Poutanen, K. 2010 Impact of dietary polyphenols on carbohydrate metabolism. International Journal of Molecular Sciences 11(4): 1365-1402.

Jaffri, J. M., Mohamed, S., Ahmad, I. N., Mustapha, N. M., Manap, Y. A., \& Rohimi, N. 2011. Effects of catechin-rich oil palm leaf extract on normal and hypertensive rats' kidney and liver. Food Chemistry 128(2): 433-441.

Jaffri, J., Mohamed, S., Rohimi, N., Ahmad, I. N., Noordin, M. M., \& Manap, Y. A. 2011. Antihypertensive and cardiovascular effects of catechin-rich oil palm (Elaeis guineensis) leaf extract in nitric oxide-deficient rats. Journal of Medicinal Food 14(78): 775-783.

Jaikaran, E. T. A. ., \& Clark, A. 2001. Islet amyloid and type 2 diabetes: from molecular misfolding to islet pathophysiology. Biochimica et Biophysica Acta (BBA) Molecular Basis of Disease 1537(3): 179-203.

Khan, N., \& Mukhtar, H. 2007. Tea polyphenols for health promotion. Life Sciences 81(7): 519-533.

Kim, J.-A. 2008. Mechanisms underlying beneficial health effects of tea catechins to improve insulin resistance and endothelial dysfunction. Endocrine, Metabolic and Immune Disorders - Drug Targets 8(2).

Lim, S.-L., Goh, Y.-M., Noordin, M. M., Rahman, H. S., Othman, H. H., Abu Bakar, N. A., \& Mohamed, S. 2016. Morinda citrifolia edible leaf extract enhanced immune response against lung cancer. Food Function 7(2): 741-751.

Lochocka, K., Bajerska, J., Glapa, A., Fidler-Witon, E., Nowak, J. K., Szczapa, T., Grebowiec, P., Lisowska, A., \& Walkowiak, J. 2015. Green tea extract decreases starch digestion and absorption from a test meal in humans: a randomized, placebo-controlled crossover study. Scientific Reports 5(12015).

Lopes, D. H. J., Colin, C., Degaki, T. L., de Sousa, A. C. V., Vieira, M. N. N., Sebollela, A., Martinez, A. M. B., Bloch, C., Ferreira, S. T., \& Sogayar, M. C. 2004. Amyloidogenicity and Cytotoxicity of Recombinant Mature Human Islet Amyloid Polypeptide (rhIAPP). Journal of Biological Chemistry 279(41): 42803-42810.

Maddux, B. A., Chang, Y.-N., Accili, D., McGuinness, O. P., Youngren, J. F., \& Goldfine, I. D. 2006. Overexpression of the insulin receptor inhibitor PC-1/ENPP1 induces insulin resistance and hyperglycemia. American Journal of PhysiologyEndocrinology and Metabolism 290(4): E746-E749.

Matanjun, P., Mohamed, S., Muhammad, K., \& Mustapha, N. M. 2010. Comparison of cardiovascular protective effects of tropical seaweeds, Kappaphycus alvarezii, Caulerpa lentillifera, and Sargassum polycystum, on high-cholesterol/high-fat diet in rats. Journal of Medicinal Food 13(4): 792-800.

Mohamed, S. 2014. Oil Palm Leaf: A New Functional Food Ingredient for Health and Disease Prevention. Journal of Food Processing \& Technology 5(2).

Mohamed, Suhaila, Lee Ming, T., \& Jaffri, J. M. 2013. Cognitive enhancement and neuroprotection by catechin-rich oil palm leaf extract supplement. Journal of the Science of Food and Agriculture 93(4): 819-827.

Moore, R. J., Jackson, K. G., \& Minihane, A. M. (2009). Green tea (Camellia sinensis) catechins and vascular function. The British
Journal of Nutrition 102(12): 1790-1802.

Motshakeri, M., Ebrahimi, M., Goh, Y. M., Matanjun, P., \& Mohamed, S. 2013. Sargassum polycystum reduces hyperglycaemia, dyslipidaemia and oxidative stress via increasing insulin sensitivity in a rat model of type 2 diabetes. Journal of the Science of Food and Agriculture 93(7): 1772-1778.

Prasain, J. K., Carlson, S. H., \& Wyss, J. M. 2010. Flavonoids and age-related disease: risk, benefits and critical windows. Maturitas 66(2): 163-171.

Rosalina Tan, R. T., Mohamed, S., Samaneh, G. F., Noordin, M. M., Goh, Y. M., \& Manap, M. Y. A. 2011. Polyphenol rich oil palm leaves extract reduce hyperglycaemia and lipid oxidation in STZ-rats. International Food Research Journal 18(1): 179-188.

Runnie, I., Salleh, M. N., Mohamed, S., Head, R. J., \& Abeywardena, M. Y. 2004. Vasorelaxation induced by common edible tropical plant extracts in isolated rat aorta and mesenteric vascular bed. Journal of Ethnopharmacology 92(2-3): 311-6.

Salleh, M. N., Runnie, I., Roach, P. D., Mohamed, S., \& Abeywardena, M. Y. 2002. Inhibition of low-density lipoprotein oxidation and up-regulation of low-density lipoprotein receptor in HepG2 cells by tropical plant extracts. Journal of Agricultural and Food Chemistry 50(13): 3693-7.

Suzuki, T., Kumazoe, M., Kim, Y., Yamashita, S., Nakahara, K., Tsukamoto, S., Sasaki, M., Hagihara, T., Tsurudome, Y., Huang, Y., Maeda-Yamamoto, M., Shinoda, Y., Yamaguchi, W., Yamada, K., \& Tachibana, H. 2013. Green Tea Extract Containing a Highly Absorbent Catechin Prevents DietInduced Lipid Metabolism Disorder. Scientific Reports 3(1): 2749.

Wu, Z., Liu, W., Jin, X., Ji, H., Wang, H., Glusman, G., Robinson, M., Liu, L., Ruan, J., \& Gao, S. 2019. NormExpression: An R Package to Normalize Gene Expression Data Using Evaluated Methods. Frontiers in Genetics 10: 400.

Zhou, H. H., Chin, C.-N., Wu, M., Ni, W., Quan, S., Liu, F., DallasYang, Q., Ellsworth, K., Ho, T., Zhang, A., Natasha, T., Li, J., Chapman, K., Strohl, W., Li, C., Wang, I.-M., Berger, J., An, Z., Zhang, B. B., \& Jiang, G. 2009. Suppression of PC$1 /$ ENPP-1 expression improves insulin sensitivity in vitro and in vivo. European Journal of Pharmacology 616(1-3): 346352. 